\title{
Celebrating philanthropy
}

\section{The 2016 Rank Prize for optoelectronics has been awarded to the inventors of the arrayed waveguide grating. Lord Rank's philanthropy deserves greater recognition.}

What do nutrition and optoelectronics have in common? The answer is that it is excellent research in these two specific areas that is rewarded by the biennial Rank Prize Funds awards - established in February 1972 by the UK businessman and philanthropist Lord (J. Arthur) Rank, shortly before his death.

These two disciplines in particular are recognized because each is connected to the two activities for which Lord Rank is most famous and held most precious to his heart - his family's flour milling and filmmaking businesses.

Lord Rank was an interesting and highly influential figure who has recently been described as a forgotten British genius (http://go.nature.com/ZzY6wK). Born in 1888 , he initially worked in his father's lucrative Yorkshire flour milling business (Rank Hovis McDougall, which is now Premier Foods) and used his wealth to establish a successful UK-based cinema and film industry in the 1930s-1950s under the umbrella of the Rank Organization. Lord Rank himself was a co-founder of Pinewood studios, purchased the Odeon cinema chain and pioneered many aspects of film production, technology and distribution.

In reference to the technology associated with film making, the optoelectronics award was created to recognize and reward important achievements at the interface of optics and electronics including vision science.

The award is selected every two years by a committee - chaired by Donal Bradley, a renowned scientist of organic optoelectronics - of 10 distinguished scientists in the UK active in the areas of optoelectronics, photonics, optics and vision science. Over a period of 12-18 months this panel collects and assesses nominations and ultimately a single achievement is selected and rewarded. The prize can be shared between up to a maximum of 5 recipients, all of whom must be living, with each receiving not less than $£ 20,000$.

"The invention or development should be of great significance scientifically, should be agenda setting, and indeed must have had a major impact, both in terms of the development of the field and its applications to benefit mankind," explained Polina Bayvel, who leads a research group on optical

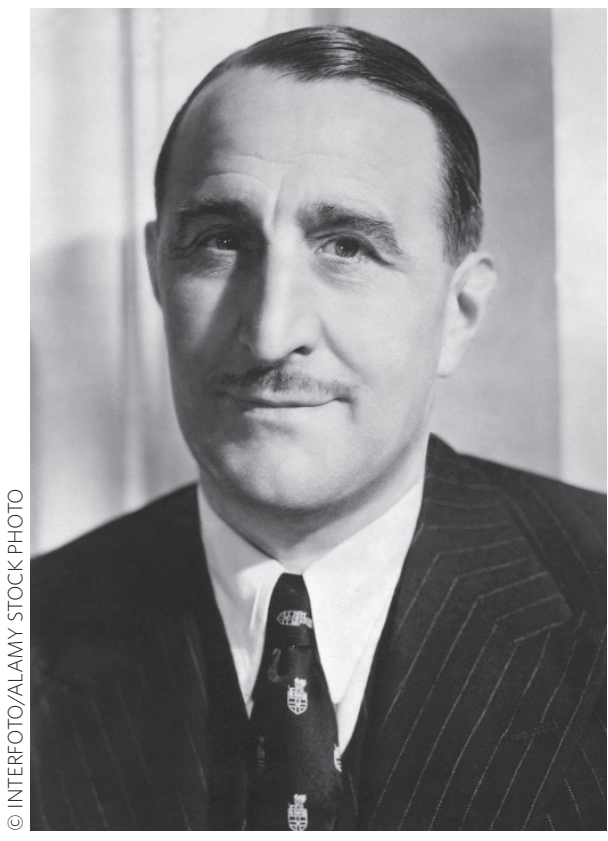

networks at University College London and has been a member of the optoelectronics committee since 2013. "The rule is that that the achievement should not have been marked by another major prize. This means that the award should not come too long after the invention, discovery or development. This is why our winners sometimes receive the Nobel Prize and not the other way around."

Indeed, looking back over the archive of former Rank Prizes, several seminal inventions have been selected for Rank Prizes very rapidly after their initial development and their inventors have then gone on to receive a Nobel Prize decades later. For example, Charles Kao and George Hockham's demonstration of low-loss clad optical fibres was awarded a Rank Prize in 1978 and then a Nobel Prize in Physics in 2009, and Shuji Nakamura, Isamu Akasaki and Hiroshi Amano who received the Nobel Prize in Physics in 2014 for the invention of the gallium nitride blue light-emitting diode were all awarded the Rank Prize in 1998 for their work on nitride light emitters.

The first Rank Prize for optoelectronics was awarded in 1976 for the development of cadmium-mercury-telluride crystals for thermal imaging detectors and subsequent awards are equally impressive. Notable achievements in photonics that have received awards (not a comprehensive list) are: optical disc recording (1986); soliton propagation in optical fibres (1991); optical tweezers (1993); the scanning confocal microscope (1995); Kerr lens laser modelocking (1997); the quantum cascade laser (1998); optical coherence tomography (2002); quantum cryptography (2006); the CMOS image sensor (2008); and the strained semiconductor laser (2014).

This brings us to today and to this year's prize that was awarded to Meint Smit (TU Eindhoven), Hiroshi Takahashi (NTT) and Corrado Dragone (Bell Labs) at a prizegiving ceremony in London on 8 February for the development and implementation of the arrayed waveguide grating (AWG). For those not familiar with the AWG, it is an integrated optical component for combining and separating the closely spaced wavelength channels used in an optical communications system employing wavelength division multiplexing (WDM).

"The use of dense WDM in optical fibre communications systems has had, and continues to have, a dramatic impact on the growth in capacity that can be provided on a single fibre," commented Bayvel. "However, in the late 1980s and 1990s it was by no means clear that the industry would go down that route. The development of AWGs - and the first designs of the 'phasar' by Smit, the first demonstration of a subnanometre demultiplexer by Takahashi and the integration of star couplers at the input and output of the demultiplexer by Dragone - formed the major advance in bringing high-capacity optical fibre communications systems to practical reality."

It should be noted that the activities of the Rank optoelectronics committee are not limited to just prize giving. It regularly organizes symposia on emerging areas of photonics - the 2016 programme includes seminars on computer vision, terahertz science, polaritonics and visual perception. It has also established a Vacation Student Scholarship Scheme to allow students to work on summer projects in photonics laboratories in the UK and in the words of Bayvel "allow them to develop an interest in this fascinating research area, and perhaps become future prize winners themselves."

For more information please visit www.rankprize.org.

Corrected after print: 12 May 2016 


\section{Correction}

In the version of the Editorial 'Celebrating

philanthropy' originally published (Nature

Photon. 10, 281; 2016), the surname of

Polina Bayvel was misspelt in one instance.

Corrected in the online versions 12 May 2016. 